\title{
Effect of different geometric changes in the dental implant abutment body on the amount of residual excess cement and retention in a cemented implant-supported prosthesis
}

\author{
Ramin Negahdari ${ }^{1, A}$, Sepideh Bohlouli ${ }^{2}, B, C$, Javad Yazdani ${ }^{3, E}$, Ali Torab ${ }^{1, A, D, F}$, Solmaz Maleki Dizaj ${ }^{4, B, E}$ \\ ${ }^{1}$ Department of Prosthodontics, Faculty of Dentistry, Tabriz University of Medical Sciences, Iran \\ ${ }^{2}$ Department of Oral Medicine, Faculty of Dentistry, Tabriz University of Medical Sciences, Iran \\ ${ }^{3}$ Department of Oral and Maxillofacial Surgery, Faculty of Dentistry, Tabriz University of Medical Sciences, Iran \\ ${ }^{4}$ Dental and Periodontal Research Center, Tabriz University of Medical Sciences, Iran \\ A - research concept and design; $\mathrm{B}$ - collection and/or assembly of data; $\mathrm{C}$ - data analysis and interpretation; \\ $\mathrm{D}$ - writing the article; $\mathrm{E}$ - critical revision of the article; $\mathrm{F}$ - final approval of the article
}

Address for correspondence

Ali Torab

E-mail: dralitorab@yahoo.com

Funding sources

Tabriz University of Medical Sciences, Iran.

Conflict of interest

None declared

\section{Acknowledgements}

This article was based on a dataset from a thesis registered at the Faculty of Dentistry of Tabriz University of Medical Sciences, Iran (No. 57577). The authors would like to thank the Vice-Chancellor for Research at Tabriz University of Medical Sciences for supporting this thesis.

Received on July 27, 2019

Reviewed on February 11,2020

Accepted on September 7, 2020

Published online on May 21, 2021

\section{Cite as}

Negahdari R, Bohlouli S, Yazdani J, Torab A, Maleki Dizaj S. Effect of different geometric changes in the dental implant abutment body on the amount of residual excess cement and retention in a cemented implant-supported prosthesis. Dent Med Probl. 2021;58(2):207-213. doi:10.17219/dmp/127347

DOI

$10.17219 / \mathrm{dmp} / 127347$

Copyright

๑ 2021 by Wroclaw Medical University

This is an article distributed under the terms of the

Creative Commons Attribution 3.0 Unported License (CC BY 3.0)

(https://creativecommons.org/licenses/by/3.0/).

\begin{abstract}
Background. Fixed implant-supported restorations are mainly used in dental implantology. In comparison with screw-retained implants, cement-retained prostheses have the following advantages: the ease of splinting implants; increased passive casting; and procedural similarity to conventional tooth-supported fixed partial dentures. Furthermore, they show reduced fracturing of components with better esthetic outcomes and an improved force direction, along with a reduced cost and less chairside time.

Objectives. The aim of this study was to evaluate the effect of different geometric changes in the dental implant abutment body on the amount of residual excess cement (REC) and the retention of cemented implant-supported prostheses.
\end{abstract}

Material and methods. Seventy-two straight abutments were categorized into 4 groups: vertical groove; 1 horizontal groove; 2 horizontal grooves; and ccontrol (with no geometric changes in the abutment). The access hole was partially filled and the cast copings were cemented using Temp-Bond ${ }^{\mathrm{TM}} \mathrm{NE}$, a non-eugenol cement. The difference in weight before and after removing the excess cement was considered as REC. Furthermore, the retention of the cast coping was measured as the force that was required to separate the cemented cast coping from the abutment.

Results. The mean REC values of the groups with 1 and 2 horizontal grooves were significantly different as compared to the control group $(p<0.05)$.

Conclusions. This study shows that the presence of 1 or 2 horizontal grooves in the abutment body significantly reduces the amount of REC in comparison with control.

Keywords: dental implants, cement, abutment type 


\section{Introduction}

Implant-supported fixed dental prostheses are a good treatment choice, which has developed into a standard of care in dentistry. This achievement may be due to the osseointegration process and the improved stability of the interfaces between the implants, the abutments and the dental prosthesis. ${ }^{1}$ Fixed implant-supported restorations are usually retained on abutments with screws or cement. ${ }^{2}$ Both abutment types have their own benefits and drawbacks. It is the clinician's responsibility to decide on the most suitable technique for each individual case. ${ }^{1}$ A recent systematic review found that the retention type (cement or screws) might not have a critical effect on the general survival of the prosthesis, but rather was responsible for the development of certain complications. ${ }^{3}$ In comparison with the screw-retained type, cemented prostheses have the following advantages: the ease of splinting implants; increased passive casting; and procedural similarity to conventional tooth-supported fixed partial dentures. ${ }^{4}$ Additionally, they show reduced fracturing of components with better esthetic outcomes and an improved force direction, along with a reduced cost and less chairside time. , $^{2,6}$ Investigators have concluded that the cement retention method is preferred over the screw-retained abutment type in the following cases: short-span prostheses with margins at or above the mucosa level; inappropriately inclined implants; and narrow-diameter crowns. ${ }^{1}$

The main disadvantage of cemented prostheses is residual excess cement (REC), which can cause the inflammation of soft tissues around the implant. ${ }^{7,8}$ Multiple research studies have shown that REC around the implant can result in a rough surface and facilitate plaque accumulation, and consequently damage soft tissues around the implant due to bacterial colonization. ${ }^{6}$ Several techniques have been proposed to reduce the amount of REC, such as minimizing the amount of cement used, ${ }^{9}$ creating a vent hole, ${ }^{9,10}$ using cements of higher viscosity, applying modified cementation methods, or the selective removal of the abutment walls. ${ }^{11,12}$

Changing the design of the abutment body is another method explored in some studies. ${ }^{6,13}$ Various modifications in the geometric design of the abutment body have been investigated, like the creation of a vent hole or a groove. Such changes made to the abutment body can act as an internal vent that may reduce REC. ${ }^{6,8}$

Unreliable retention is another concern about cemented restorations. ${ }^{14}$ To circumvent this drawback, the following methods to increase the retention rate have been proposed: changes in the abutment surface texture; modified cementation methods; and the selective removal of the abutment walls. ${ }^{13,14}$ The abutment surface can be changed by creating grooves. Such changes can reduce REC and improve the retention of the prosthesis. ${ }^{12}$

\section{Objectives}

The aim of the present study was to investigate how different geometric changes in the dental implant abutment body influence the amount of REC and the retention of cement-retained implant restorations. The null hypothesis stated that all of these modifications could reduce REC and increase the retention of cement-retained implant restorations.

\section{Material and methods}

\section{Abutment modification}

The sample size was calculated with the Power and Sample Size Calculator (PS) software, v. 3.1 (https://pspower-and-sample-size-calculation.software.informer. $\operatorname{com} / 3.1 /)$ as 13 samples per group $(n=13)$. This was based on the results of a study by Wadhwani et al., ${ }^{6}$ with $\alpha=0.05$ and a power of $80 \%$. To increase the validity of the study, 18 samples were considered for each group, resulting in a total of 72 samples. The straight abutments (OSSTEM ${ }^{\circledR}$; Osstem Implant, Busan, South Korea) used in this study were $5.5 \mathrm{~mm}$ in length, $4.5 \mathrm{~mm}$ in diameter and $1 \mathrm{~mm}$ in gingival height.

\section{Coping fabrication}

In order to mold the coping crown, the access holes of the abutments were carefully blocked out with wax during the laboratory procedures. For uniformity between the study groups, a three-dimensional (3D) printer was used to design the coping patterns. Since the abutments were similar prior to implementing the changes, one of the abutments was scanned using a Maestro ${ }^{\circledR} 3 \mathrm{D}$ scanner (AGE Solutions, Pontedera, Italy), and then designed with the Exocad software (Exocad, Darmstadt, Germany), considering a cement space relief of $50 \mu \mathrm{m}$. After that, the scanned and designed copings were made with a $3 \mathrm{D}$ printer (Prodent ${ }^{\circledR} 3 \mathrm{D}$ printer; Bonyan Mechatronic, Tehran, Iran) and a light-curing moldable 3D resin (Freeprint ${ }^{\circledR}$ cast; Detax, Ettlingen Germany), and casted with base metal alloys (Sankin ${ }^{\circledR}$, non-beryllium; Dentsply Sirona, Tokyo, Japan). The cast copings were examined under an optical microscope (Nikon, Tokyo, Japan) at $\times 20$ magnification to assist in adaptation to their corresponding abutments and any irregularities were removed with a milling round of $1 / 2$. A vertical mark was created on the copings in the corresponding area of the flat side of the abutments to guide the placement of the copings on the abutments.

The abutments were tightened with the ratchet of the OSSTEM system by using a torque of $25 \mathrm{~N} \cdot \mathrm{cm}$ on the fixture analogs of the same system and mounted 
in acrylic blocks to help with the operation. Each of the 4 study groups contained 18 individual abutments with the indicated modifications. In group 1 , each abutment had a vertical groove measuring $0.5 \mathrm{~mm} \times 0.5 \mathrm{~mm}$ from the occlusal surface of the abutment up to $1 \mathrm{~mm}$ above the finish line; it was created with a bur (KaVo Dental, Biberach, Germany). Each abutment of group 2 had a horizontal groove $(0.5 \mathrm{~mm} \times 0.5 \mathrm{~mm})$ that was created at a distance of $3 \mathrm{~mm}$ from the occlusal edges. The abutments of group 3 had 2 horizontal grooves $(0.5 \mathrm{~mm} \times 0.5 \mathrm{~mm})$ with a 1-millimeter distance. The control group (group 4) consisted of 18 abutments with no changes in the abutment body.

\section{Cementation}

Before cementation, the abutment screw access channel was filled up to $1 \mathrm{~mm}$ on the occlusal surface with Coltosol $^{\circledR}$ (Coltène/Whaledent, Altstätten, Switzerland). To measure the amount of REC, the weight of coping/ abutment/analog/acrylic block was determined with an A\&D scale (EK-300i; A\&D Company, Tokyo, Japan). A dental cement (Temp-Bond ${ }^{\mathrm{TM}}$ NE; Morris Dental Company, Dublin, Ireland) was mixed according to the manufacturer's instructions and applied to the intaglio surface until the coping was filled in approx. $75 \%$. The weight of coping/abutment/analog/acrylic block with cement was then measured before placing the coping on the abutment. Next, the copings were placed - initially by finger pressure - on the mounted abutments, followed by a pressure of $5 \mathrm{~kg}$ for $7 \mathrm{~min}$ with a universal testing machine (model HSK-S; Hounsfield Test Equipment, Redhill, UK). The excess cement was then removed with a plastic scaler and coping/abutment/ analog/acrylic block was weighted again after cleaning (Fig. 1).

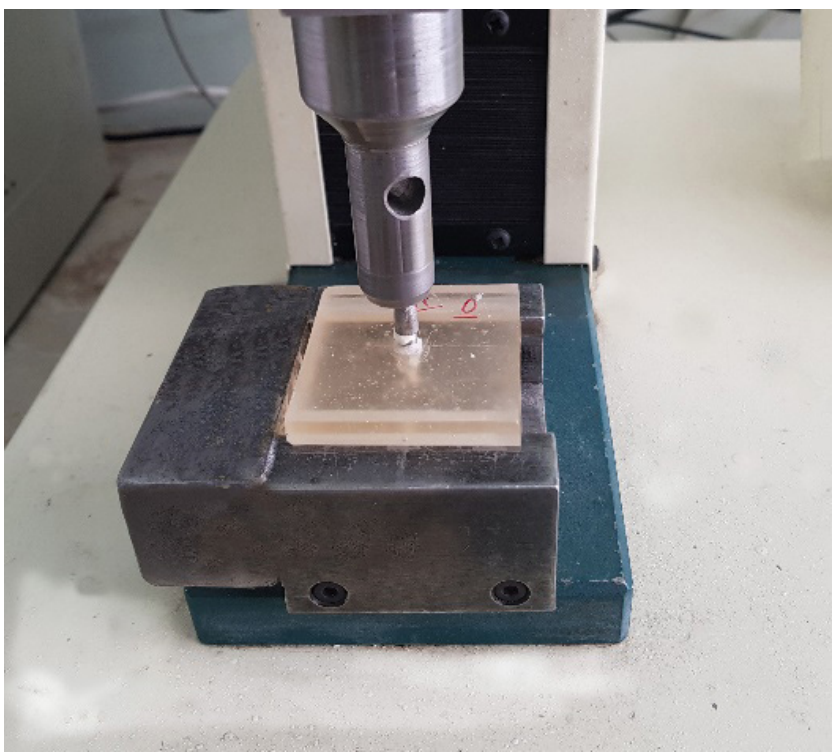

Fig. 1. Cementation process

\section{REC evaluation}

The following formula was used to measure REC (Equation 1):

REC $=$ (weight of coping/abutment/analogue/acrylic block after cementation and removing excess) [gr] (1) - (weight of coping/abutment/analogue/acrylic block with cement before cementation)

\section{Evaluation of retention}

The samples were then incubated at $37^{\circ} \mathrm{C}$ and $100 \%$ relative humidity for $24 \mathrm{~h}$. The specimens were assembled in a universal testing machine and subjected to a pull-out test (retention) at a crosshead speed of $1 \mathrm{~mm} / \mathrm{min}$. The force required to remove the copings was recorded in newtons (Fig. 2).

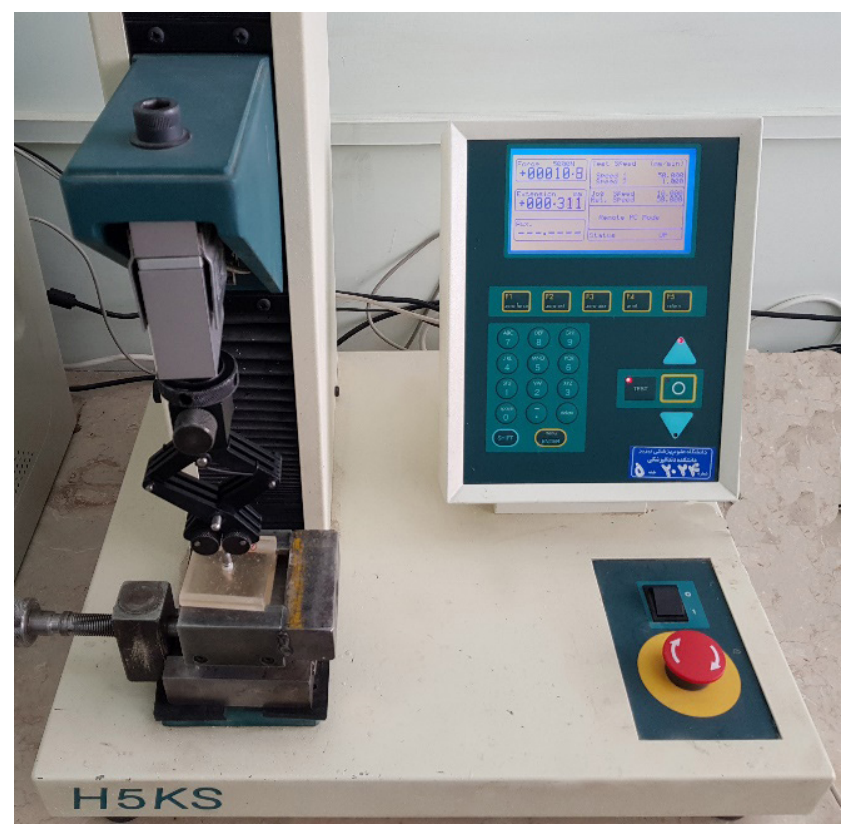

Fig. 2. Evaluation of the retention

\section{Statistical analyses}

Data was analyzed using descriptive statistical methods (mean $(M) \pm$ standard deviation $(S D)$ ), and then compared between the groups. The normality of data was analyzed with the Kolmogorov-Smirnov test. Statistically significant differences between the studied groups in the mean REC values were investigated with the Kruskal-Wallis test. Statistically significant differences between pairs of groups were analyzed using the Mann-Whitney $U$ test. The statistical analyses were carried out by means of the SPSS Statistics for Windows, v. 17.0 (SPSS Inc., Chicago, USA), and a $p$-value $<0.05$ was considered statistically significant. 


\section{Results}

The $M$ and $S D$ values for the 2 variables - REC and retention - in the study groups are presented in Table 1. We found that the mean REC value was the highest in the 'no groove' control group. Group 3 (2 horizontal grooves) showed the lowest mean REC value. The mean retention value was the highest in group 3 ( 2 horizontal grooves) and the lowest in group 1 (vertical groove).

Table 1. Residual excess cement (REC) and retention in the study groups

\begin{tabular}{|c|c|c|c|c|}
\hline Variable & Group & $M$ & SD & $p$-value \\
& vertical groove & 0.0450 & 0.01295 & \\
& 1 horizontal groove & 0.0406 & 0.01349 & \\
REC [gr] & 2 horizontal grooves & 0.0367 & 0.01029 & $0.002^{1 *}$ \\
& no grooves & 0.0544 & 0.01464 & \\
& total & 0.0442 & 0.01432 & \\
& vertical groove & 103.8444 & 13.37945 & \\
& 1 horizontal groove & 111.3833 & 25.33394 & \\
Retention [N] & 2 horizontal grooves & 119.1944 & 19.39701 & $0.102^{2}$ \\
& no grooves & 108.4944 & 13.95609 & \\
& total & 110.7292 & 19.10013 & \\
& & & &
\end{tabular}

M - mean; SD - standard deviation; ${ }^{1}$ Kruskal-Wallis test; ${ }^{2}$ one-way ANOVA; * statistically significant.

The normal distribution of the 2 variables - REC and retention - was analyzed using the Kolmogorov-Smirnov test and we found that the distribution of the REC variable was not normal; therefore non-parametric tests were used to examine the associated hypotheses $(p<0.05)$. Additionally, we found that the distribution of the retention variable was normal, and therefore parametric tests were used to examine the associated hypotheses $(p<0.05)$. Figure 3 shows REC for the study groups and Fig. 4 shows retention for the study groups. To examine if there was any statistically significant difference between the studied groups in the mean REC values, the Kruskal-Wallis test was used. The results showed a statistically significant difference in the REC means between the study groups $(p<0.05)$ (Table 1$)$. The Mann-Whitney $U$ test was then used to compare the groups with each other; the results are presented in Table 2. There were statistically significant differences in the REC means between the 'no grooves' control group and groups 2 and 3 - with 1 and 2 horizontal grooves, respectively. The mean REC value in the 'no grooves' group was higher than the means in those 2 groups $(p<0.05)$. The mean REC value in the 'vertical groove' group was significantly higher as compared to the group with 2 horizontal grooves $(p<0.05)$. There were no statistically significant differences in the REC means between other

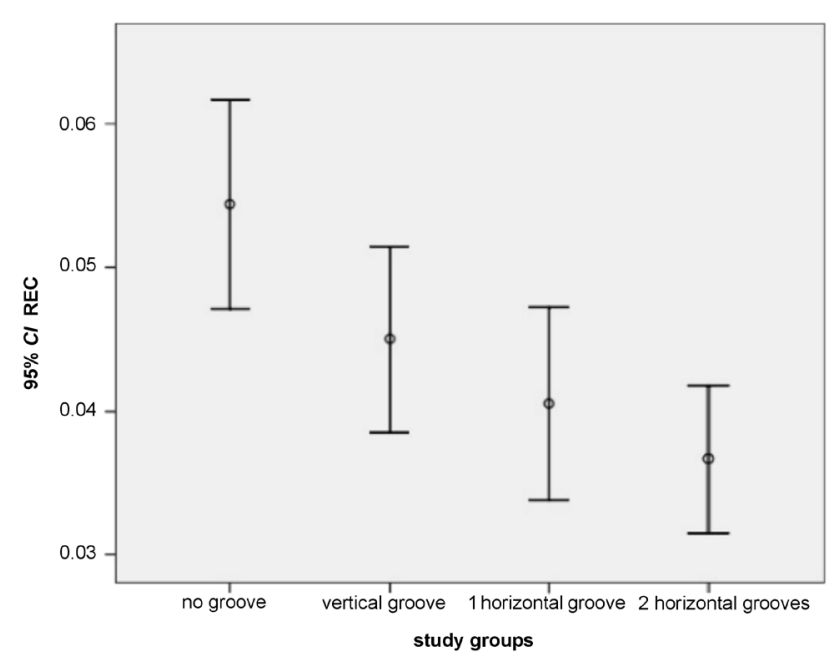

Fig. 3. Residual excess cement (REC) in the study groups $\mathrm{Cl}$ - confidence interval.

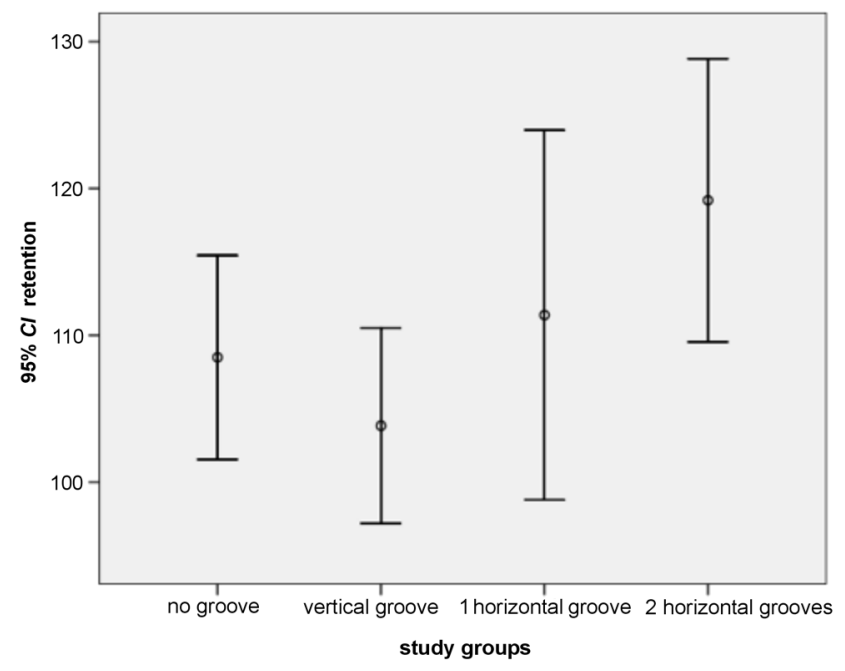

Fig. 4. Retention in the study groups

study groups. To test any statistically significant difference in the mean retention between the study groups, the one-way analysis of variance (ANOVA) was used. There was no statistically significant difference in the mean retention between the study groups (Table 1 ).

Table 2. Comparison of the mean amount of residual excess cement (REC) among the study groups (Mann-Whitney $U$ test)

\begin{tabular}{|c|c|c|}
\hline \multicolumn{2}{|c|}{ Group comparisons } & $p$-value \\
\hline \multirow{3}{*}{ No grooves } & vertical groove & 0.060 \\
\hline & 1 horizontal groove & $0.007^{*}$ \\
\hline & 2 horizontal grooves & $<0.001^{*}$ \\
\hline \multirow{2}{*}{ Vertical groove } & 1 horizontal groove & 0.256 \\
\hline & 2 horizontal grooves & $0.043^{*}$ \\
\hline 1 horizontal groove & 2 horizontal grooves & 0.489 \\
\hline
\end{tabular}

* statistically significant. 


\section{Discussion}

Implant treatment can be a challenging clinical condition, which requires a high level of communication between the surgeon, the technician and the restoring dentist. ${ }^{15,16}$ Today, cement-retained implant-supported prostheses are widely used. However, they might have disadvantages in comparison with screw-retained ones, including REC and unreliable retention after cementation. The present study aimed to introduce modifications in the abutment that would address these problems. ${ }^{17-19}$

The main disadvantage of cement-retained implantsupported prostheses is REC, which can cause the inflammation of soft tissues around the implant. ${ }^{5,7,8}$ Various studies have shown that REC around the implant may result in a rough surface and facilitate plaque accumulation, and damage soft tissues around the implant due to bacterial colonization. ${ }^{5,7}$ A cohort study found that the direct cause of damage in $80 \%$ of the soft tissues surrounding the implant was due to the colonization of bacteria on the excess cement. ${ }^{6}$ For this reason, numerous studies have investigated methods that reduce REC.

In this study, the null hypothesis about the effect of the changes made in the abutments on the amount of excess cement was rejected, and we found that only the addition of horizontal groove(s) to the abutment body resulted in reduced excess cement. On average, the amount of excess cement in the group with 1 horizontal groove was $0.0406 \mathrm{gr}$, while it was $0.0367 \mathrm{gr}$ in the group with 2 horizontal grooves. Both values were statistically significantly different as compared to the control group $(0.0544$ gr; $p<0.05)$. We propose that perhaps horizontal grooves act as a reservoir and because of the circumferential shape around the abutment, they house some excess cement during the insertion of the coping. However, a vertical groove is created only in a specific area, and its function is limited and localized. Additionally, the groove might facilitate cement exit before filling the superior space of the screw hole.

Based on the reports, creating a groove in the abutment body can increase the retention of the crown and reduce the amount of REC without weakening the abutment. ${ }^{6,8}$ However, in this study, we found that the mean retention was higher in the group with 2 horizontal grooves as compared to other groups and lower in the 'vertical groove' group. Nonetheless, this failed to reach statistical significance when analyzed using the one-way ANOVA. This may be explained by the dimensions of the created grooves. Lewinstein et al. designed grooves during the construction of the abutment, which allowed them to design larger grooves. ${ }^{13}$ However, in this study, the abutments were prefabricated, and therefore it was not possible to create a deep groove without affecting the abutment body resistance. The use of cements of higher fracture strength in these conditions might reveal the effect of creating such grooves on increasing retention. In recent years, some studies reported the importance of creating grooves together with other modifications. In a recent study by Shrivastav, the influence of different surface modifications on the retention of a zinc phosphate cement-retained implant was investigated. ${ }^{20}$ The work investigated the effects of circumferential grooves with sandblasting (group 1) and with a bur modification (group 2) against control (group 3). It was shown that modifications in group 2 resulted in improving the retention of a bridge cemented on implant abutments. ${ }^{20}$ Sahu et al. reported that abutments with the milled and sandblasted modifications exhibited the highest retention, followed by abutments with retentive grooves, and then by abutments with the milled surfaces once the cast copings were cemented to implant abutments with a polymer-based cement. ${ }^{21}$

There are no specific guidelines available on the appropriate amount of cement to be used. Using a minimal amount of cement might decrease the cement rejection rate, but this method can result in problems such as inadequate retention and leakage. ${ }^{5,9,14}$ Similarly, excessive amounts of cement can cause problems such as the inappropriate placement of the coping and high REC values. ${ }^{14}$ However, the amount of cement used in this study was greater than the amount needed for flooding the relief space between the coping and the abutment. Although various methods have been proposed to adjust the appropriate cement amount, for clinicians, the control of the cement amount during the clinical stages is uncertain. ${ }^{22}$ Moreover, the amount of cement used in this study is the most commonly used for the cementation process by clinicians. ${ }^{10}$ Modified cementation methods are another option to reduce REC. ${ }^{11,12}$ Such methods, despite being effective in reducing $\mathrm{REC}$, might not be clinically feasible due to their time-consuming nature, especially in cases with higher number of implants. One method is to seat the restoration filled with cement on a mock abutment (an analog abutment) extraorally. This abutment could be a stock analog or a customized analog made from polyvinyl siloxane. ${ }^{14}$ Recently, Chee et al. explored 4 cementation methods for their effect on the amount of excess cement. ${ }^{12}$ They studied the cementation of the internal marginal area of the crown (group 1), cementation on the apical half of the axial walls of the crown (group 2), cementation to all axial walls of the interior surface of the crown, excluding the occlusal surface (group 3), and in group 4 - the crown filled with cement, and then seated on the putty index formed to the internal configuration of the restoration (a cementation device). The least amount of excess cement was found in group 4. The authors concluded that this method led to a uniform layer of the luting agent, which might be due to the internal surface of the crown leaving minimal excess cement when the restoration was seated. ${ }^{12}$

The creation of a vent hole in the restoration surface is also proposed to reduce REC. ${ }^{8,13}$ Although this modification was introduced initially to reduce the seating discrepancies in tooth-supported restorations, it was found 
to have a negative effect on the integrity of the crown structure. Additionally, complex laboratory procedures are needed for its construction, after which it requires to be restored again by the dentist in the clinic. ${ }^{14}$ In a study by Wadhwani et al., a change in the abutment body as 2 opposite double-sided holes in the axial wall of the abutment was more effective than a normal abutment in decreasing REC, as the hole was used as a means to transfer cement to the abutment screw access space. ${ }^{6}$ In a finite element study by Rodriguez et al., an abutment design with 8 holes in the abutment margin area improved the pattern of the flow of cement into the abutment screw access space, thereby decreasing the rejection rate of the cement. ${ }^{8}$ Recently, Chen et al. tested the effect of a vent hole on the retentive force of a restoration. They showed that the retentive force of restorations with a vent hole was equal to or better than of those without a vent hole. ${ }^{23}$

Different methods have been proposed to block the abutment screw access hole, but there are currently no guidelines in this regard. Studies have shown that the partial filling of the screw access channel can act as a reservoir for excess cement and can also increase the retention of the restorations cemented with a temporary cement. ${ }^{24}$ In this study, some space within the abutment was preserved to prevent further rejection of cement and increase the retention, in addition to relative re-accessible blocking.

Unreliable retention is another concern about cemented restorations. The main factors affecting retention include abutment dimensions, framework properties and the characteristics of the cement used. ${ }^{14}$ In some circumstances, like small occlusogingival dimensions, where procedures are limited, other methods, such as changing the surface of the abutment body, are used. ${ }^{14}$

Changing the abutment surface texture by sandblasting also increases the retention of the crown, but this method is not quite feasible in commonly used implants. Additionally, the selective removal of the abutment walls increases retention by decreasing taper and creating vertical walls. ${ }^{10,13,14}$ However, this method increased the odds of abutment body weakening.

\section{Conclusions}

The purpose of the current study was to assess how different geometric changes in the dental implant abutment body influence the amount of REC and the retention of cemented implant-supported prostheses. It was found that the REC means in groups 2 ( 1 horizontal groove) and 3 (2 horizontal grooves) were statistically significantly different from control group 4 (no grooves) $(p<0.05)$. There was a significant difference between the lowest mean REC value (group 1) and the highest mean REC value (group 3) $(p<0.05)$. However, 1 and 2 horizontal grooves in the abutment body effectively reduced REC in comparison with other groups.

\section{ORCID iDs}

Ramin Negahdari (1) https://orcid.org/0000-0001-5867-5500 Sepideh Bohlouli (i) https://orcid.org/0000-0001-9712-3979 Javad Yazdani (1) https://orcid.org/0000-0002-5900-890X

Ali Torab (1) https://orcid.org/0000-0002-0340-871X

Solmaz Maleki Dizaj (i) https://orcid.org/0000-0003-4408-1300

\section{References}

1. Wittneben JG, Joda T, Weber HP, Brägger U. Screw retained vs. cement retained implant-supported fixed dental prosthesis. Periodontol 2000. 2017;73(1):141-151. doi:10.1111/prd.12168

2. Misch CE, Resnik R. Misch's Avoiding Complications in Oral Implantology. eBook. Maryland Heights, USA: Mosby - Elsevier; 2017:30-42.

3. Wittneben JG, Millen C, Brägger U. Clinical performance of screwversus cement-retained fixed implant-supported reconstructions - a systematic review. Int J Oral Maxillofac Implants. 2014;29(Suppl):84-98. doi:10.11607/jomi.2014suppl.g2.1

4. Vindasiute E, Puisys A, Maslova N, Linkeviciene L, Peciuliene V, Linkevicius T. Clinical factors influencing removal of the cement excess in implant-supported restorations. Clin Implant Dent Relat Res. 2015;17(4):771-778. doi:10.1111/cid.12170

5. Wilson TG Jr. The positive relationship between excess cement and peri-implant disease: A prospective clinical endoscopic study. J Periodontol. 2009;80(9):1388-1392. doi:10.1902/jop.2009.090115

6. Wadhwani C, Piñeyro A, Hess T, Zhang H, Chung KH. Effect of implant abutment modification on the extrusion of excess cement at the crown-abutment margin for cement-retained implant restorations. Int J Oral Maxillofac Implants. 2011;26(6):1241-1246.

7. Wadhwani C, Rapoport D, La Rosa S, Hess T, Kretschmar S. Radiographic detection and characteristic patterns of residual excess cement associated with cement-retained implant restorations: A clinical report. J Prosthet Dent. 2012;107(3):151-157. doi:10.1016/ S0022-3913(12)60046-8

8. Rodriguez LC, Saba JN, Meyer CA, Chung KH, Wadhwani C, Rodrigues DC. A finite element analysis of novel vented dental abutment geometries for cement-retained crown restorations. Clin Exp Dent Res. 2016;2(2):136-145. doi:10.1002/cre2.33

9. Pauletto N, Lahiffe BJ, Walton JN. Complications associated with excess cement around crowns on osseointegrated implants: A clinical report. Int J Oral Maxillofac Implants. 1999;14(6):865-868.

10. Wadhwani $\mathrm{C}$, Chung $\mathrm{KH}$. Effect of modifying the screw access channels of zirconia implant abutment on the cement flow pattern and retention of zirconia restorations. J Prosthet Dent. 2014;112(1):45-50. doi:10.1016/j.prosdent.2014.01.007

11. Wadhwani CPK, Piñeyro AF. Implant cementation: Clinical problems and solutions. Dent Today. 2012;31(1):56-63.

12. Chee WWL, Duncan J, Afshar M, Moshaverinia A. Evaluation of the amount of excess cement around the margins of cement-retained dental implant restorations: The effect of the cement application method. J Prosthet Dent. 2013;109(4):216-221. doi:10.1016/S0022-3913(13)60047-5

13. Lewinstein I, Block Z, Lehr Z, Ormianer Z, Matalon S. An in vitro assessment of circumferential grooves on the retention of cement-retained implant-supported crowns. J Prosthet Dent. 2011;106(6):367-372. doi:10.1016/S0022-3913(11)60149-2

14. Nematollahi F, Beyabanaki E, Alikhasi M. Cement selection for cement-retained implant-supported prostheses: A literature review. J Prosthodont. 2016;25(7):599-606. doi:10.1111/jopr.12361

15. Parnia F, Yazdani J, Javaherzadeh V, Maleki Dizaj S. Overview of nanoparticle coating of dental implants for enhanced osseointegration and antimicrobial purposes. J Pharm Pharm Sci. 2017;20(0):148-160. doi:10.18433/J3GP6G

16. Moshaverinia A, Schoenbaum TR. Cemented implant restorations in the aesthetic zone: Biological, functional, and aesthetic considerations. In: Schoenbaum TR, ed. Implants in the Aesthetic Zone. A Guide for Treatment of the Partially Edentulous Patient. New York, USA: Springer; 2019:247-266. doi:10.1007/978-3-319-72601-4

17. Messias A, Rocha S, Wagner W, et al. Peri-implant marginal bone loss reduction with platform-switching components: 5 -year postloading results of an equivalence randomized clinical trial. J Clin Periodontol. 2019;46(6):678-687. doi:10.1111/jcpe.13119 
18. Abjanich $\mathrm{JH}$, Orenstein $\mathrm{IH}$. Prosthodontic considerations in dental implant restoration. In: Greenberg AM, Prein J, eds. Craniomaxillofacial Reconstructive and Corrective Bone Surgery: Principles of Internal Fixation Using the AO/ASIF Technique. New York, USA: Springer; 2002:232-261. doi:10.1007/b97845

19. Choi JW, Choi KH, Chae HJ, et al. Load-bearing capacity and retention of newly developed micro-locking implant prosthetic system: An in vitro pilot study. Materials (Basel). 2018;11(4):564. doi:10.3390/ ma11040564

20. Shrivastav M. Effect of surface treatments on the retention of implant-supported cement-retained bridge with short abutments: An in vitro comparative evaluation. J Indian Prosthodont Soc. 2018;18(2):154-160. doi:10.4103/jips.jips_251_17

21. Sahu N, Lakshmi N, Azhagarasan NS, Agnihotri Y, Rajan M, Hariharan R. Comparison of the effect of implant abutment surface modifications on retention of implant-supported restoration with a polymer based cement. J Clin Diagn Res. 2014;8(1):239-242. doi:10.7860/JCDR/2014/7877.3931

22. Wadhwani C, Hess T, Piñeyro A, Opler R, Chung KH. Cement application techniques in luting implant-supported crowns: A quantitative and qualitative survey. Inter J Oral Maxillofac Implants. 2012;27(4):859-864.

23. Chen JR, Nagao K, Tomotake Y, Oka K, Hada M, Ichikawa T. Influence of a vent hole on the retentive force of a cement-retained superstructure before/after thermocycling. Prosthodont Res Pract. 2006;5(3):157-160. doi:10.2186/prp.5.157

24. Emms M, Tredwin CJ, Setchell DJ, Moles DR. The effects of abutment wall height, platform size, and screw access channel filling method on resistance to dislodgement of cement-retained, implant-supported restorations. J Prosthodont. 2007;16(1):3-9. doi:10.1111/j.1532-849X.2006.00150.x 